\title{
Main Critical Side Effects Associated with Chemotherapy Used in Cancer Treatment
}

\author{
Bassam Abdul Rasool Hassan* \\ Clinical Pharmacy Discipline, School of Pharmaceutical Sciences, University of Sains Malaysia, 11800, Minden, Penang, Malaysia
}

\section{Introduction}

Cancer has become a major killer in the world which almost surpasses the cardiovascular diseases and will become the main lethal cause in this century. Although the global war against cancer leads to remarkable gain in understanding the main molecular mechanism for the cancer cell, this progress is still considered as slow and not enough especially in case of treatment of common solid tumor in adults. Besides that there are so many types of serious side effects caused by the tumor itself be it solid cancer or hematological cancer. Moreover these side effects are not only caused by cancer itself but also from the chemotherapy treatment which is used for it and the most critical side effects are associated with the chemotherapy treatment more than the cancer disease. Therefore it became an obligate matter for all clinicians to be aware of these chemotherapy side effects.

\section{Chemotherapy Background}

Chemotherapy was developed and used since the Word War I from the chemical weapon program of the United State of America (USA), since that era it became one of the most important treatment for cancer disease. The main mechanism for its working is by attaching and destroying the cancer cells which are characterized by their high multiplication and growth speed $[1,2]$. Even though when comparing chemotherapy with other types of treatments, it still remain potentially high risk with many side effects which are difficult to manage. Chemotherapy requiresthe involvement of various clinical professionals during its various stages of administration and enormous patient health care is needed to overcome its side effects $[1,3]$.

\section{Chemotherapy Side Effects}

The goal of chemotherapy is to be as effective as possible with tolerable side effects, since the dose of chemotherapy will be toxic to the cancer cells as well as to the normal cells. A proportion of the cancer patients suffer from only mild side effects whereas others may suffer from serious side effects. Occurrence of specific side effects will vary according to the chemotherapy or medications used. The most common side effects experienced are nausea and vomiting, anemia, hair loss, bleeding (thrombocytopenia), hyperuricemia, bone marrow depression, alopecia and mucositis. So different parameters must be taken into consideration to prevent, reduce and overcome these side effects [3-5].

\section{Classifications of Chemotherapy Side Effects}

The side effects commonly associated with chemotherapy treatment are classified as:

1. Acute, which develop within 24 hours after chemotherapy administration.

2. Delayed, which develop after 24 hours and up to 6 to 8 weeks after chemotherapy treatment.

3. Short term, combination of both acute and delayed effect.
4. Late/ long term, which develop after months or years of chemotherapy treatment.

5. Expected, which developed among $75 \%$ of the patients.

6. Common, occurred in $25 \%-75 \%$ of the patients.

7. Uncommon, happened is less than $15 \%$ of the patients.

8. Rare, occur in only $5 \%$ of the patients.

9. Very rare, occur with less than $1 \%$ of the patients [3-5].

\section{Conclusion}

Therefore it is an obligate matter for all clinicians to follow up all the cancer patients who receive chemotherapy in order to prevent or palliate any of these side effects which may appear. Moreover it is important to focus on research within this field in order to detect the proper ways which can help to overcome these side effects.

\section{References}

1. Brighton D, Miriam W (2005) The Royal Marsden Hospital Handbook of Cance Chemotherapy. London: Elsevier/Churchill Livingstone.

2. Kelland LR (2005) Cancer cell biology, drug action and resistance. (edn) The Royal Marsden Hospital Handbook of Cancer Chemotherapy. London: Elsevier/Churchill Livingstone.

3. Rizzo T, Cloos R (2002) Chemotherapy. In thackery, (edn) The gale encyclopedia of cancer detroit, gale group.

4. Abrams AC (2001) Drugs used in oncologic disorders. Clinical Drug Therapy. (36thedn), Ontario: Canadian Pharmacists Association.

5. Koda-kimble IYY, Wayne A, Kradjan, BJG, Brain KA, Robin IC (2002) Applied therapeutics the Clinical use of drugs. In Troy D (Edn) Hand book of applied therapeutics. Philadelphia: Williams \& Wilkins.
*Corresponding author: Bassam Abdul Rasool Hassan, Clinical Pharmacy Discipline, School of Pharmaceutical Sciences, University of Sains Malaysia, 11800, Minden, Penang, Malaysia, Tel: +6-016-423-0950; E-mail: bassamsunny@yahoo.com

Received June 28, 2012; Accepted July 04, 2012; Published July 06, 2012

Citation: Rasool Hassan BA (2012) Main Critical Side Effects Associated with Chemotherapy Used in Cancer Treatment. Pharmaceut Anal Acta 3:e1113. doi:10.4172/2153-2435.1000e113

Copyright: (c) 2012 Rasool Hassan BA. This is an open-access article distributed under the terms of the Creative Commons Attribution License, which permits unrestricted use, distribution, and reproduction in any medium, provided the original author and source are credited. 